\title{
PERCEPÇÕES DE ACADÊMICOS DE ENFERMAGEM SOBRE O PROCESSO MORTE E MORRER: IMPLICAÇÕES NA FORMAÇÃO PROFISSIONAL
}

Christiane Tereza Aleixo dos Santos ${ }^{1}$ Suelen da Silva Miranda (In memorian) ${ }^{1}$ Karina de Oliveira Freitas ${ }^{1}$ Esleane Vilela Vasconcelos ${ }^{1}$

\begin{abstract}
https://orcid.org/0000-0003-1643-2935 https://orcid.org/0000-0003-4645-5900 https://orcid.org/0000-0002-8708-1944 https://orcid.org/0000-0002-5083-050X
\end{abstract}

Objetivo: Analisar e descrever as percepções dos acadêmicos de enfermagem frente ao processo de morte e morrer e suas implicações para a formação profissional. Método: Estudo descritivo de abordagem qualitativa, realizada com 30 acadêmicos de enfermagem, no período de agosto a outubro de 2018, por meio da entrevista semiestruturada e analisada pela técnica de análise temática. Resultados: Os depoimentos foram sintetizados em quatro unidades temáticas: "A morte e seus significados": "A morte e seu ensino na formação acadêmica"; "Sentimento de preparo para o enfrentamento do processo morte e morrer"; e "A postura do futuro profissional frente às situações que englobam a morte". Conclusão: Dentre as percepções encontradas, destaca-se a visão da morte como um processo natural/biológico, bem como, o despreparo enfrentado pelos acadêmicos no lidar com a finitude, dado a forma de abordagem do tema na graduação, implicação que se não for sanada influenciará na atuação destes futuros profissionais.

Descritores: Educação em Enfermagem, Morte, Educação Superior.

\section{PERCEPTIONS OF NURSING ACADEMICS ABOUT THE DEATH AND DYING PROCESS: IMPLICATIONS IN VOCATIONAL TRAINING}

Objective: To analyze and describe the perceptions of nursing students regarding the process of death and dying and its implications for professional training. Method: Descriptive study with a qualitative approach carried out with 30 nursing students, from August to October 2018, through the semi-structured interview and analyzed using thematic analysis technique. Results: The statements were summarized in four thematic units: "Death and its meanings"; "Death and its teaching in academic formation"; "Feeling prepared to face the death and dying process"; and "The attitude of the future professional in the face of situations that include death". Conclusion: Among the perceptions found, the view of death as a natural / biological process stands out, as well as the unpreparedness faced by academics in dealing with finitude, given the way of approaching the theme in undergraduate courses, an implication that if not addressed will influence in the performance of these future professionals. Descriptors: Nursing Education, Death, Higher Education.

\section{PERCEPCIONES DE ACADÉMICAS DE ENFERMERÍA SOBRE EL PROCESO DE MUERTE Y MORIR: IMPLICACIONES EN LA FORMACIÓN PROFESIONAL}

Objetivo: analizar y describir las percepciones de los estudiantes de enfermería sobre el proceso de muerte y morir y sus implicaciones para la formación profesional. Metodo: Estudio descriptivo con enfoque cualitativo, realizado con 30 estudiantes de enfermería, de agosto a octubre de 2018, a través de la entrevista semiestructurada y analizada mediante la técnica de análisis temático. Resultados: Las declaraciones se resumieron en cuatro unidades temáticas: "La muerte y sus significados": "La muerte y su enseñanza en la formación académica"; "Sentirse preparado para enfrentar el proceso de muerte y morir"; y "La actitud del futuro profesional ante situaciones que incluyen la muerte". Conclusión: Entre las percepciones encontradas, se destaca la visión de la muerte como un proceso natural / biológico, así como la falta de preparación que enfrentan los académicos al tratar con la finitud, dada la forma de abordar el tema en la graduación, una implicación que si no se aborda influirá en el desempeño de estos futuros profesionales.

Descriptores: Educación en Enfermería, Muerte, Educación Superior. 


\section{INTRODUÇÃO}

O processo de morte e morrer são fenômenos dificeis de se aceitar, principalmente para os profissionais da saúde que durante toda sua formação acadêmica tem o ensino-aprendizado voltado para cura e/ou reestabelecimento da saúde. Vivenciar este processo, que é a única certeza da vida, ainda tem como produto sentimentos de ansiedade, medo e angústia, assim como o sentimento de fracasso profissionall-2.

No ambiente hospitalar, principalmente nas Unidades de Terapia Intensiva, a morte é um evento esperado, onde os profissionais de saúde, idealmente os enfermeiros que se encontram mais intimamente ligados aos pacientes, têm a consciência de que em qualquer momento de sua vida profissional, vão ter contato com a morte de algum destes ${ }^{3}$. Apesar de conviverem diretamente e por mais tempo com os pacientes, isso não significa que os profissionais de enfermagem estejam totalmente preparados para o enfrentamento do processo de morte e morrer ${ }^{4}$

Em alguns dos cursos de graduação em enfermagem no Brasil foram incorporadas disciplinas que contribuem para a compreensão do processo de morte e morrer, no entanto entende-se que ainda há a carência de reflexões e discussões acerca do tema, sendo necessário o fornecimento de subsídios tanto para a equipe docente quanto para os discentes, para que estes possam ser preparados para o enfretamento desse processo em sua vida profissional ${ }^{5-6}$.

Assim, considerando que a morte ainda causa desconforto e angústia em quem a vivencia, torna-se relevante desenvolver um estudo sobre as percepções de acadêmicos de enfermagem sobre o processo de morte e morrer, com o intuito de identificar as carências do ensino quanto a temática, para diminuir os aspectos negativos ligados a concepção da mesma, assim como tentar fortalecer a abordagem do tema no decorrer do curso de enfermagem, para que os alunos possam lidar da melhor maneira possivel com a ela, bem como possam oferecer uma melhor assistência aos envolvidos no processo.

Abordar esta temática é necessária para que o acadêmico de enfermagem reconheça seus limites e assim busque preparo tanto profissional quanto ético para trabalhar com a morte. Diante disso, objetivou-se analisar e descrever as percepções sobre o processo de morte e morrer de acadêmicos de enfermagem da Universidade Federal do Pará e suas implicações para a formação profissional. O alcance desses objetivos contribuirá para o preenchimento de lacunas existentes sobre a percepção de acadêmicos sobre a temática e possibilitará uma reflexão sobre as necessidades de ensino da temática nos cursos de saúde, assim como colaborará, enquanto conhecimento, para formação profissional destes, quanto a forma de lidarem com a morte.

\section{METODO}

\section{Tipo de estudo}

Trata-se de um estudo descritivo com abordagem qualitativa.

\section{Participantes da pesquisa}

Os participantes da pesquisa foram 30 graduandos de enfermagem do oitavo e do nono semestre da Faculdade de Enfermagem da Universidade Federal do Pará. Os critérios de inclusão foram: maior de 18 anos; ter cursado a atividade curricular Enfermagem em Centro de Terapia Intensiva e manifestar concordância em participar do estudo assinando o termo de consentimento livre e esclarecido (TCLE). O não atendimento desses critérios implicou na exclusão dos sujeitos.

\section{Local do estudo}

O estudo foi realizado na Faculdade de Enfermagem da Universidade Federal do Pará do município de Belém, estado do Pará, Brasil.

Coleta dos dados com explicitação dos instrumentos e procedimentos

A coleta de dados foi realizada no período de agosto a outubro de 2018, por meio de entrevista semiestruturada, contendo as seguintes questões: $O$ que seria a morte para você? Admitindo-se que a UTI é um ambiente onde a evolução do paciente é de total instabilidade, o que você sentiria ou já sentiu ao presenciar a morte de um paciente? Qual seria sua conduta caso um paciente em fase terminal the fizesse a seguinte pergunta: "Eu vou morrer?" Você se sente preparado como futuro profissional enfermeiro para atuar mediante situações que envolvam a morte de pacientes como possibilidades do seu dia a dia? Você acredita que a sua formação acadêmica está sendo eficiente para the preparar com a possibilidade de acontecimentos que envolvam o processo de morte e morrer? Assim como perguntas referentes aos dados sociodemográficos dos participantes como sexo, idade, estado civil e religião.

Estes questionamentos forneceram os subsídios necessários para interpretações e alcance dos objetivos propostos. As entrevistas foram individuais, realizadas de acordo com a disponibilidade de horário dos discentes, bem como de local, com agendamento prévio entre as pesquisadoras e os discentes. A maior parte das entrevistas foi realizada na FAENF (Faculdade de Enfermagem), algumas nos hospitais em que os discentes estavam em prática, e outras na própria residência dos entrevistados, com duração média de 15 minutos. Os depoimentos foram gravados e posteriormente transcritos.

\section{Procedimentos de análise dos dados qualitativos}

Para análise dos dados optou-se pela técnica de Análise de Conteúdo, que tem um caráter essencialmente qualitativo, no qual se utiliza um conjunto de técnicas para descrever o conteúdo emitido no processo de comunicação, seja ele por 
meio de falas ou de textos. Tal técnica consiste na contagem da frequência com que os relatos de uma entrevista se repetem favorecendo a captação dos núcleos de significados que compõem uma comunicação, tornando-se evidentes por sua frequência aumentada, de forma que favorece a identificação de sentidos relevantes para contextualização da realidade estudada ${ }^{7}$.

A partir desta, os depoimentos foram sintetizados em quatro unidades temáticas: "A morte e seus significados"; "A morte e seu ensino na formação acadêmica"; "Sentimento de preparo para o enfrentamento do processo morte e morrer"; e "A postura do futuro profissional frente as situações que englobam a morte".

\section{Procedimentos éticos}

Para o desenvolvimento deste estudo, foram respeitados os aspectos éticos previstos na Resolução 466/12, que dispõe sobre pesquisas com seres humanos. O projeto foi submetido ao Comitê de Ética da Instituição e obteve sua aprovação com o Parecer consubstanciado de número 2.262.507.

\section{RESULTADOS}

Dos 30 graduandos de enfermagem que participaram do estudo, 24 eram do sexo feminino e seis do sexo masculino. A faixa etária variou entre 21 e 52 anos, destes, 20 eram solteiros(as) e oito casados(as) e dois em união estável. Quanto à religião, 17 se declararam católicos, 10 evangélicos, um espírita e dois sem religião.

A seguir serão apresentados as quatro unidades temáticas identificadas nas entrevistas.

\section{A morte e seus significados}

"Para mim, a morte é um fechamento de um ciclo." (D08)

"Bom a morte pra mim é o fim de tudo, é a fase final de todo ser humano, todos nós um dia vamos morrer e essa é a única certeza que nós temos." (D28)

"A morte fisicamente é a interrupção definitiva do organismo, ou seja, é a incapacidade do nosso corpo manter a homeostasia por algum motivo (...)" (D20)

"Biologicamente falando a morte é a cessação de todas as nossas atividades vitais é quando nosso corpo não consegue mais manter o equilibrio (...)" (D30)

"A morte para mim é uma passagem, eu tenho encarado a morte como o início de uma outra vivência (...)." (D27)
"Olha pra mim em especial a morte é uma passagem dessa vida material para uma vida espiritual, nós saímos desse plano e vamos para um outro plano celestial." (D29)

\section{A morte e seu ensino na formação acadêmica}

"Nós assistimos um filme sobre isso, sobre o preparo do cadáver e tudo mais, e foi muito pouco (...). Tem que ter em várias etapas da formação da enfermagem, desde o início da graduação, já que é um processo natural da vida e vamos vivencia-lo no nosso dia a dia." (DOI)

“Eu não vejo que a graduação ela tem me preparado pra esse momento de perda de morte do paciente, na verdade o único momento que a gente falou sobre isso foi uma aula em que a gente assistiu a um filme e respondeu um questionário sobre o assunto, mas eu penso que deveria ser abordado durante todos os semestres." (D27)

“Para gente foi ensinado o processo de vida, não foi ensinado o processo de morrer, então por isso a gente ainda tem essa dificuldade dentro da gente de ter medo de falar da morte." (DI7)

"A academia não está preparando a gente para essas possibilidades de morte e morrer, por que ainda é uma formação muita mecânica, muito tradicional, tipo você tem que aprender isso, por que é isso que vai salvar a vida do paciente (...) eu não vejo essas atividades curriculares de uma forma transversal." (DO5)

"Nas minhas práticas foram poucos professores que nos fizeram ter uma visão assim de olhar a morte como algo natural do ciclo da vida (...)." (DIO)

Sentimento de preparo para o enfrentamento do processo morte e morrer

“Eu me sinto preparada, até por que com um tempo a gente aprende a lidar, por que no meio que a gente trabalha não tem como fugir disso." (DO2)

"Eu não me sinto preparada para lidar com essa situação, mesmo porque a vivência tanto teórica quanto prática é insuficiente para ensinar a gente a 
lidar com esse processo de morte e morrer de um paciente." (D28)

"Eu não me sinto preparada, mas acredito que vou acabar me preparando na prática profissional mesmo." (D22)

"Acho que só o tempo e a vivência profissional te preparam, na verdade não é preparar acho que eles te ensinam em como ir lidar com a morte de um paciente sem entrar em estado de sofrimento por se sentir impotente." (D29)

\section{A postura do futuro profissional frente as situações que englobam a morte}

A exposição desta última unidade contempla o questionamento sobre qual seria a conduta desses discentes, como profissionais, se um paciente em fase terminal the fizesse a seguinte pergunta: Eu vou morrer?

Frente ao questionamento, a maioria dos participantes referiu que não saberia como lidar com essa responsabilidade de uma forma integral e que por isso pediria auxílio de outros profissionais, principalmente do serviço de psicologia. Nos relatos também houve quem "apelasse" para religiosidade, atribuindo tal conhecimento apenas a Deus, assim como quem simplesmente não saberia como agir.

“Eu não sei exatamente o que eu faria, mas eu acho que pensando e analisando, eu não iria falar que ele iria morrer (...) eu iria buscar uma pessoa mais capacitada para conversar com o paciente." (DO3)

"Eu ia tentar conectar palauras para diminuir a ansiedade dele e posteriormente deixar ele um pouco mais calmo, mas com certeza eu ia consultar o serviço de psicologia pra aconselhar ele." (DI6)

"Acho que chamaria a psicologia para conversar com a pessoa pra que ela tenha uma assistência mais integral." (D30)

“(...) eu acho que se ele me perguntasse se vai morrer eu teria que entender muito do caso dele." (D21)

"Essa é uma pergunta muito difícil porque ai sel lá não sei nem te dizer porque, mas assim eu não sei como seria a minha conduta." (D22)

\section{DISCUSSÃO}

Estudos sobre a morte e seus fenômenos, tem despertado cada vez mais o interesse de acadêmicos da área da saúde, o que por sua vez tem gerado uma maior abertura para se discutir e refletir sobre a temática de maneira mais natural ${ }^{8-9}$.

Apesar de se entender que a morte é inevitável, que faz parte do processo biológico da vida humana e ocorre constantemente, falar sobre ela, ainda traz certo desconforto, visto que lembra o indivíduo de sua finitude e de seus familiares. A percepção da morte e de seus fenômenos, é construida diariamente dentro de uma sociedade, tendo como variável a formação cultural e a crença religiosa de cada indivíduo, que influenciarão na forma de entende-la ${ }^{9-12}$

De acordo com Ivo, Pedroso ${ }^{13}$ as palavras não são suficientes para descrever o processo de morte e morrer. Assim definir a morte em um único conceito torna-se difícil, pois cada pessoa tenta à sua maneira simbolizá-la, de acordo com seu conhecimento e vivência.

Diante dos resultados alcançados, pôde-se identificar nos relatos esta miscigenação de informações, onde cada participante atribuiu a morte um conceito diferente, uns ligados a questão de completude de um ciclo biológico e/ ou a distúrbios biológicos que impedem o funcionamento do organismo, e outros a termos místicos e religiosos, que trazem a ideia de "passagem" deste plano a outro, sendo ideias que perpassam pela ciência, filosofia e teologia e que os auxiliarão no processo de enfrentamento da morte e de seus impasses.

Não obstante pareça fácil na visão científica, o conceito de morte ainda é um acontecimento complexo, com múltiplos fatores e interpretações envolvidas, fato que vem sendo modificado ao longo da história, com a inclusão da temática nos cursos de formação superior voltados a saúde ${ }^{6}$.

Mesmo com tal inclusão, é possível evidenciar a deficiência da formação acadêmica de enfermeiros nas instituições de ensino do Brasil, frente a temática que envolve a terminalidade da vida e do processo que a cerca ${ }^{3,4}$. Dado que é reforçado com os achados deste estudo, onde se destaca a insuficiência de discussões e abordagens superficiais sobre o processo de morte e morrer na academia, fato que culminará na formação de profissionais sem preparo para tal assistência, por não conseguirem lidar com a morte de uma maneira natural e saudável, e que poderão desenvolver sentimentos como o de culpa e fracasso, tendo em vista que foram educados para salvar vidas ${ }^{(6,9-10,14)}$

Dentre as muitas falas dos graduandos de enfermagem, pôde-se identificar a dificuldade física e emocional deles em falar sobre a morte e de realizar a comunicação de más notícias aos que vivenciam este processo. O que 
demonstra que estes futuros profissionais de saúde não estão sendo educados e nem preparados para enfrentar o cuidar no processo de morte e morrer ${ }^{15}$. Fato este que é coerente, dado a forma deficiente com que este conteúdo fora ministrado segundo os alunos, sendo poucos os que informaram acreditar estar preparado para este momento, competência que provavelmente fora "alcançada" com o tempo e possiveis experiências pessoais, havendo também aqueles que acreditam que serão capacitados em sua vida profissional, na prática diária.

Para Lima e seus colaboradores ${ }^{2}$ o modo de cuidar de pessoas em processo de morte e morrer e de seus familiares, precisa ser bem abordada em toda a formação em saúde, de maneira que se explore os diversos aspectos culturais e religiosos, os tabus e as concepções das pessoas sobre a morte, a fim de reduzir a ansiedade causada pelo processo de finitude e contribuir para a melhoria do atendimento em saúde às pessoas que necessitam deste cuidado.

Segundo Lima e seus colaboradores ${ }^{(16)}$, a formação do enfermeiro assim como dos demais profissionais de saúde deve ser completa, unindo a ciência e a formação humanística para que haja o pleno exercício profissional. Desta maneira, entende-se que as instituições de ensino superior, por meio de sua equipe docente, deve ser mediadora do conhecimento em saúde, de forma a proporcionar um ensino de qualidade que promova o desenvolvimento de habilidades e a construção de profissionais conscientes ${ }^{17}$.

Desta maneira, a formação em saúde não pode ter como referência apenas a enfermidade, como no modelo biomédico, onde se objetiva o cuidado em prol do diagnóstico e do tratamento, mais sim, buscar compreender as pessoas de forma ampla e humanizada, afim de atende-las em todas as suas necessidades ${ }^{18}$. Sendo assim, é necessário a existência de debates sobre a morte e o morrer, em sala de aula e durante as práticas, que fomentem no alunado um pensamento crítico e natural, para que possam desenvolver habilidades para a realidade que irão vivenciar ${ }^{19}$.

Por todo o exposto, destaca-se a fragilidade existente em alguns cursos de enfermagem quanto aos aspectos psicossociais da profissão, voltados a finitude, que tem como consequência acadêmicos sem preparo psicológico para lidar com o processo de morte e morrer, e por conseguinte futuros profissionais que terão que aprender a lidar com esta situação em seu dia a dia, podendo por falta de preparo desenvolver certos sofrimentos psíquicos.

Assim, sugere-se a reestruturação teórico-prática dos currículos dos cursos de graduação em enfermagem com o objetivo de ampliar o conhecimento sobre o processo de morte e morrer, no intuito de contribuir para a formação do enfermeiro e por conseguinte na prestação dos cuidados ao paciente e família que perpassam por esse processo, além de cooperar na realização de novos estudos sobre a temática.

\section{Limitações do estudo}

Este estudo apresenta como limitação ter sido realizado em apenas uma faculdade de enfermagem sendo representada por um número restrito de participantes, porém, suficientes para responder o objetivo aqui proposto.

\section{Contribuições do estudo para a prática}

Este estudo traz como contribuição para prática, o refletir da necessidade de uma formação em saúde mais completa e humanizada quanto a temática abordada, a fim de que se entregue ao mercado de trabalho profissionais preparados e qualificados para uma boa prestação de serviços tanto para a vida, quanto para a morte de seus pacientes.

\section{CONCLUSÃO}

Os dados aqui apresentados, ainda que limitados à realidade de um curso de graduação em enfermagem, puderam evidenciar as percepções dos graduandos de enfermagem sobre o processo de morte e morrer, dentre as quais tem-se o "fechamento de um ciclo", "um processo natural/biológico", "ausência dos sinais vitais" e "uma passagem", que vai da vida física para a vida espiritual.

Além disso, pôde-se evidenciar o despreparo enfrentado por eles para lidarem com o processo de finitude, dado a forma superficial e rápida de abordagem da temática durante a formação acadêmica, o que indica a necessidade de se expandir o espaço para a informação, discussão e reflexão sobre este processo tão complexo, de forma a oportunizar aos acadêmicos o real compreender da morte e do morrer, implicações estas que se não forem sanadas terão forte influência na formação e atuação destes futuros profissionais, podendo por falta do preparo para tal assistência desenvolver sentimentos de culpa e fracasso e até mesmo ter sua saúde mental e emocional comprometida.

Contribuições dos Autores: Christiane Tereza Aleixo dos Santos: Concepção, análise, interpretação dos dados e revisão final do artigo; Suelen da Silva Miranda (In memorian): Concepção, análise e interpretação dos dados; Karina de Oliveira Freitas: Redação do artigo e revisão crítica; Esleane Vilela Vasconcelos: Concepção, análise, interpretação dos dados e revisão final do artigo. 


\section{REFERÊNCIAS}

1. Kovács MJ. Educação para a morte. Psicol Ciênc Profissão [Internet]. 2005 [cited 2020 fev 15];25(3):48497. Available from: http://www.scielo.br/scielo.php?script=sci_arttext\&pid=S1414-98932005000300012.

2. Lima R, Borsatto AZ, Vaz DC, Pires ACF, Cypriano VP, Ferreira MA. A morte e o processo de morrer: ainda é preciso conversar sobre isso. REME - Rev Min Enferm [Internet]. 2017 [cited 2020 fev. 10];21:e-1040. Available from: http://www.reme.org.br/artigo/detalhes/1178.

3. Araújo RM, Álvares ACM, Jesus ALS. O impacto do processo de finitude e morte de pacientes no cotidiano do profissional de enfermagem. Rev Inic Cient Ext [Internet]. 2018 [cited 2020 fev 15];1(Esp.4):400-4. Available from: https://revistasfacesa.senaaires.com.br/index.php/iniciacao-cientifica/article/download/127/85/.

4. Oliveira ES, Agra G, Morais MF, Feitosa IP, Gouveia BLA, Costa MML. O processo de morte e morrer na percepção de acadêmicos de enfermagem. Rev enferm UFPE on line [Internet]. 2016 [cited 2020 fev 18];10(5):1709-16. Available from: https://periodicos.ufpe.br/revistas/revistaenfermagem/article/ download/13546/16319.

5. Stochero HM, Nietsche EA, Salbego C, Pivetta A, Schwertner MVE, Fettermann FA, et al. Sentimentos e dificuldades no enfrentamento do processo de morrer e morte por graduandos de enfermagem. Aquichan [Internet]. 2016 [cited 2020 fev 15];16(2):219-29. Available from: http://bases.bireme.br/cgi-bin/wxislind.exe/iah/online/?lsisScript-iah/iah. xis\&src=google\&base=LILACS\&lang=p\&nextAction=lnk\&exprSearch=791092 indexSearch=lD.

6. Mons SC, Pereira GS, Lima LLM, Leite CN, Fernandes RTP. Estratégias de defesa no processo de morte e morrer: um desafio aos profissionais da enfermagem. Res Soc Dev [Internet]. 2020 [cited 2020 fev 10];9(2):e190922139. Available from: https://www.researchgate.net/publication/338426348_Estrategias_ de_defesa_no_processo_de_morte_e_morrer_um_desafio_aos_profissionais_da_enfermagem.

7. Bardin L. Análise de conteúdo. 4. ed. Lisboa: Edições 70, p.95-127, 2010.

8. Trevisano RG, Almeida JV, Barreto CA. O olhar da enfermagem no processo de luto. Rev Saúde Foco

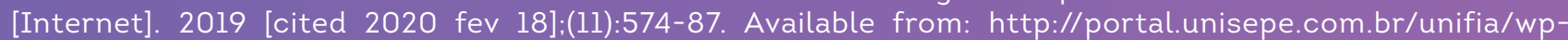
content/uploads/sites/10001/2019/05/052_O-OLHAR-DA-ENFERMAGEM-NO-PROCESSO-DE-LUTO.pdf. 9. Couceiro FBL, Bonini LMM, Afférri C, Imada HN, Nictheroy LM, Silva RA. A percepção da morte e do morrer por estudantes de medicina. Diálogos interdisciplinares [Internet]. 2019 [cited 2020 fev 15];8(10):113. Available from: http://www.seer.ufal.br/index.php/nuspfamed/article/view/2526.

10. Gonçalves JR, Simões JRS. A percepção do enfermeiro no lidar com a morte durante a assistência. Rev JRG [Internet]. 2019 [cited 2020 fev 15];II(5):166-82. Available from: http://www.revistajrg.com/index.php/ jrg/article/view/77.

11. Lysakowski S, Menin GE. Utilização de simulação clínica no ensino sobre terminalidade da vida na enfermagem: relato de experiência. Rev Docência Ens Sup [Internet]. 2019 [cited 2020 fev 15];9(1):e002559. Available from: https://periodicos.ufmg.br/index.php/rdes/article/view/2559.

12. Martins LA, Cunha JHS, Ferreira LA, Frizzo HCF, Carvalho LBCP. Significado da morte de pacientes para os profissionais de saúde em unidade de terapia intensiva. REFACS [Internet]. 2019 [cited 2020 fev 13];7(4):448-57. Available from: https://idonline.emnuvens.com.br/id/article/view/691.

13. Ivo OP, Pedroso KO. O Processo da Morte e do Morrer: uma Visão dos Acadêmicos de Enfermagem. ID online Rev Multidisc Psicologia [Internet]. 2017 [cited 2020 fev 15];11(34):271-80. Available from: https:// idonline.emnuvens.com.br/id/article/view/691/970.

14. Lima MJV, Andrade NM. A atuação do profissional de saúde residente em contato com a morte e o morrer. Saúde soc [Internet]. 2017 [cited 2020 fev 15];26(4):958-72. Available from: http://www.scielo.br/ scielo.php?script=sci_arttext\&pid=S010412902017000400958.

15. Vasques TCS, Lunardi VL, Silva PA, Avila LI, Silveira RS, Carvalho KK. Equipe de enfermagem e complexidades do cuidado no processo de morte-morrer. Trab Educ Saúde [Internet]. 2019 [cited 2020 fev 15];17(3):e0021949. Available from: http://www.scielo.br/scielo.php?script=sci_arttextEpid=S1981-77462019000300504.

16. Lima JMA, Santos TS, Guimarães MN, Rocha VLG, Santos EA. "Reflections on tanatology for healthcare professionals working in intensive care: An integrative review". Int J Dev Res [Internet]. 2019 [cited 2020 fev 18];9(12):32717-22. Available from: http://www.journalijdr.com/reflections-tanatology-healthcareprofessionals-working-intensive-care-integrative-review.

17. Heliodoro EA, Rosa DOS. Aspectos éticos e legais da morte encefálica conhecidos por estudantes de enfermagem. Enferm Foco [Internet], 2019 [cited 2020 mai 04];10(1):140-5. Available from: http://revista. cofen.gov.br/index.php/enfermagem/article/view/1489/510.

18. Santos ATS, Oliveira CB, Passos MC, Andrade ASA, Gallotti FCM. Integralidade do cuidado na formação do enfermeiro: visões e vivências do acadêmico de enfermagem. Enferm Foco [Internet], 2019 [cited 2020 mai 04];10 (1): 122-6. Available from: http://revista.cofen.gov.br/index.php/enfermagem/article/view/1397/507. 19. Santos TF, Pintarelli VL. Educação para o Processo do Morrer e da Morte pelos Estudantes de Medicina e Médicos Residentes. Rev Bras Educ Med [Internet]. 2019 [cited 2020 fev 17];43(2):5-14. Available from: http://www.scielo.br/scielo.php?script=sci_abstract\&pid=S0100-55022019000200005\&lmg=pt\&nrm=iso. 